\title{
NosOtros, manual para disolver el capitalismo, de Ricardo Espinoza Lolas
}

\author{
Ricardo Roque Baldovinos \\ Universidad Centroamericana \\ "José Simeón Cañas", UCA
}

Con este nuevo título, Ricardo Espinoza Lolas culmina la trilogía del NosOtros, serie que arrancó con Hegel y las nuevas lógicas del mundo y del estado (2016) y continuó con Capitalismo \& empresa. Hacia una revolución del NosOtros (2018). Este conjunto nos da una idea de la intensidad del trabajo del autor y de la racha de productividad que atraviesa en este momento de madurez intelectual.

Aunque tiene un punto de partida es filosófico NosOtros, manual para disolver el capitalismo no es un libro convencional de filosofía, por su prosa lúdica y por el diálogo que entabla con diversas manifestaciones de la producción cultural contemporánea. El sustento filosófico lo expuso con detenimiento en el primer título de la trilogía. Allí no sólo proponía una nueva lectura de Hegel, sino que mostraba que esta era necesaria para comprender el mundo actual, atrapado en un aparente sin salida luego del colapso de los paradigmas ideológicos y políticos del siglo XX. Espinoza Lolas contribuía así a la nueva tendencia que propone releer al filósofo alemán no ya desde La fenomenología del espíritu, sino desde la que hoy se considera su obra fundamental: La ciencia de la lógica, que trata menos de la dialéctica que del método absoluto, el cual engloba a esta última como uno de sus momentos. Lejos de la conocida acusación de cierto marxismo envejecido, para quien Hegel opera una hipóstasis de las ideas en detrimento de los procesos materiales, el método absoluto permite aprehender la realidad en su imbricación de materia y espíritu. Esto lo comprendió el propio Marx entendió al llevar a cabo una relectura a fondo de La ciencia de la lógica antes de emprender la redacción de El capital. El autor también nos recuerda que el subtítulo del libro - ¿Cómo se es revolucionario hoy?- pretende dar nueva vida a la idea de revolución, mas ya no como una continuación de lógicas políticas jacobinas heredadas desde la revolución francesa, con sus quiebres históricos súbitos y tajantes, sino como la posibilidad de minar 
y transformar el sistema capitalista desde sus entrañas.

Por otra parte, el segundo volumen de la serie dilucidaba la lógica del capitalismo, la cual no radica sólo en la construcción de un nuevo sistema económico, sino de una nueva forma de subjetividad, la que obliga al sujeto a seguir el mandato del "emprende" y que, llevado hasta sus últimas consecuencias, ha terminado por pervertir la civilización moderna en lo que el autor designa como el capitalismo hacendal chapuza y militarizado. Aún así, continuaba sosteniendo el autor, este mandato puede subvertirse, y redirigir su energía en la construcción de un tejido socio histórico revolucionario.

El tercer tomo es el más propositivo de la serie, de allí la palabra "manual" del subtítulo. Esta obra explora con más detenimiento las posibilidades de revolucionar el capitalismo. Para entender mejor el alcance de esta importante obra, es clave comprender que, al ser un nuevo modo de subjetividad la creación principal del capitalismo no podemos colocarnos de manera cómoda desde un afuera, llámese este socialismo, anticolonialismo, feminismo, ecologismo, etc... El libro sigue así una tradición de crítica ideológica para la cual la ideología no es una falsa conciencia, que se impugna desde una verdad racionalmente establecida, sino la subje- tivación misma, cuya superación requiere de caminos más arduos. La emancipación no es entonces posible desde un sujeto iluminado por la ciencia o investido del designio de la historia, sino sólo desde el minucioso hilvanar de un nuevo tejido socio histórico que integre lo mejor de luchas sociales, memorias e invención de nuevas formas de vida.

Como se dijo, este libro desarrolla su argumento en un cercano diálogo con obras de arte contemporáneo y productos culturales de consumo popular, como los cómics y los filmes de aventuras. Ello se puede detectar en los nombres de algunos capítulos como el primero, “ $\mathrm{iDesactivando}$ a Hulk!". Para el autor, la saga de los superhéroes de Marvel escenifica con diafanidad al sujeto capitalista. Por otra parte, al final de ese mismo capítulo, contrapone a esta lógica egocéntrica, homogenizadora y violenta tres modos de hacer que le resisten y que resultan vitales en la búsqueda de una salida: los tejedores, es decir los políticos en su sentido más etimológico, griego, quienes conjugan las voluntades y deseos de la polis; los historiadores, que tejen una memoria que nos enfrenta a cómo llegamos al mundo actual y que insiste, por tanto, en que nada está dado de manera definitiva; $y$, finalmente, los visionarios, quienes atisban mundos alternativos en nuevas configuraciones sensibles. Es en este tercer grupo donde entran, los artistas a quienes dedica buena 
parte de un libro profusamente ilustrado con sus obras.

Antes de adentrarnos en el aporte de los visionarios, es importante mencionar el segundo capítulo “ Amar al otro aunque duela”, el cual, por medio de una meditación del amor, nos entrega la concepción filosófica de lo humano que subyace a este esfuerzo intelectual. Es una concepción de lo humano como apertura ineludible hacia lo otro. Esta es la razón de ser del neologismo del NosOtros. El sujeto capitalista se ha planteado como un yo que se afirma vaciando al otro, reduciéndolo a un objeto a su plena disposición. Esta reducción del otro no es una operación filosófica abstracta, sino la lógica social vigente, de explotación de la naturaleza y del ser humano, que ha hecho posible el mundo actual. El autor retoma para su argumento los planteamientos de Heidegger y Zubiri que evidencian que somos constitutivamente con otros. A esto, añade que la forma por antonomasia de esa apertura al otro es el Amor que vierte nuestra subjetividad hacia fuera y nos permite salir del laberinto narcisista del yo moderno.

En esta dirección, cobra pleno sentido el último capítulo, dedicado a comentar el trabajo de distintos artistas latinoamericanos, entre ellos dos de El Salvador: Beatriz Cortez y Ferrán Caum. El autor propone una comprensión del arte que va mucho más allá de ser un espacio de refugio o de compensación frente a la alienación moderna. El arte invoca lo sensible material, lo que media la idea con el cuerpo. El arte no sólo construye mundos virtuales, sino que al hacerlo propone formas materiales de experiencia que son anticipos de otras maneras de estar juntos. En el arte contemporáneo destaca trabajos que nos insertan en nuevas coordenadas de experiencias, de ser con otros, de ser, en su propio vocabulario, un NosOtros. Federica Matta diseña e interviene espacios públicos, que invitan a los moradores de la ciudad a relacionarse de otra forma con su entorno. Beatriz Cortez, a través de sus esculturas e instalaciones, sitúa en el paisaje de San Salvador y de Los Ángeles, la memoria de las víctimas del conflicto salvadoreño o la presencia de migrantes que el sistema invisibiliza. Ferrán Caum, en su animación Víctimas de Guernica, nominada al premio Goya de 2018, nos invita a establecer una conexión intempestiva, entre la obra ya consagrada de Picasso y la experiencia de las víctimas del conflicto armado en El Salvador, aún a la espera de justicia.

La relación de Espinoza Lolas con el arte no sólo radica en el recurso a obras artísticas como invitaciones al pensamiento, sino en la textura misma del libro. Su escritura se conecta no sólo la tradición del ensayo latinoamericano sino también con el montaje como prin- 
cipio constructivo el cual, más que una forma ingeniosa de exposición del contenido, es una forma de pensar que apela a lo corporalsensible para destejer las evidencias que nos envuelven. Espinoza Lolas nos entrega, en definitiva, un nuevo libro provocador, concebido para convocar a un colectivo de lectores más amplio que el usual público académico, pero nos ofrece también un planteamiento filosófico que evidencia la tan necesaria conexión entre el pensamiento y el compromiso de construcción del mundo por venir.

\section{Referencias bibliográficas}

- Espinoza Lolas, R. (2016). Hegel y las nuevas lógicas del mundo y del estado. Madrid: Akal.

- Espinoza Lolas, R. (2018). Capitalismo \& Empresa. Hacia una Revolución del NosOtros. Santiago: Libros Pascal Editores.

- Espinoza Lolas, R. (2019). NosOtros, manual para disolver el capitalismo. Morata: Madrid. 